\title{
A TEMÁTICA AMBIENTAL E AS DIFERENTES COMPREENSÕES DOS PROFESSORES DE FÍSICA EM FORMAÇÃO INICIAL
}

\section{Environmental themes and different conceptions of future Physics teachers}

Luciano Fernandes Silva ${ }^{1}$. Luiz Marcelo de Carvalho ${ }^{2}$

Resumo: Procuramos identificar as concepções dos licenciandos de física em relação à temática ambiental, bem como analisamos as propostas por eles elaboradas e os obstáculos que se lhes apresentam quando decidem tratar alguns aspectos da problemática ambiental em suas atividades de ensino. Os dados foram coletados a partir do desenvolvimento de algumas atividades na disciplina de Prática de Ensino oferecida a alunos concluintes de um curso de Licenciatura em Física de uma universidade pública no estado de São Paulo. Os dados evidenciam que as concepções que os licenciandos elaboram sobre a temática ambiental podem tornar-se obstáculos para a incorporação desses aspectos em suas propostas de ensino. Da mesma forma, não há, por parte dos licenciandos, uma compreensão mais ampla quanto ao significado da temática ambiental, quanto às implicações do movimento ambientalista para as práticas culturais e pedagógicas e possibilidades de exploração de temas ambientais associados a propostas de ensino de física.

Palavras-chave: Temática ambiental. Ensino de física. CTSA.

\begin{abstract}
In this paper we try to identify some conceptions of trainee physics teachers about environmental issues and to analyze physics teaching activities proposed by them when they decide to include environmental themes in their teaching practices. This investigation also allowed us to identify some obstacles that trainee physics teachers had while dealing with environmental problems in their classes. The data collection was carried out through the development of some activities in a class called Practice of Physics Teaching, which is part of the curriculum of an Undergraduate Physics course (Teaching License) of a public university of the state of São Paulo. Data analysis pointed out that future physics teachers' conceptions about environmental issues can prevent them from including such topics in their educational practices. Data analysis also revealed that trainee physics teachers don't have a broad understanding of the significance of environmental issues and the implications of environmentalism for cultural and pedagogical practices.
\end{abstract}

Keywords: Environmental themes. Physics teaching. STS.

\footnotetext{
${ }^{1}$ Instituto de Ciências Exatas, Departamento de Física e Química, Universidade Federal de Itajubá. Av. BPS, s/no, Bairro Pinheirinho. Itajubá, MG, Brasil.37.500-903. lufesilva@uol.com.br

${ }^{2}$ Departamento de Educação, Universidade Estadual Paulista "Júlio de Mesquita Filho", campus de Rio Claro. Rio Claro, SP, Brasil.
} 
Silva, L. F.; Carvalho, L. M.

\section{Introdução}

Os níveis de degradação ambiental experimentados por diferentes setores da sociedade após a segunda metade do século XX têm merecido a atenção de diversos grupos sociais. A partir desse momento, passa a ser mais frequente a tentativa de se compreender a relação sociedade-natureza. Essas compreensões assumem um papel central nas reflexões, propostas de ações e tomadas de decisões relacionadas com a problemática ambiental.

São muitas e variadas as concepções sobre a temática ambiental, porém, interessanos, em especial, aquelas que são elaboradas a partir da tentativa de explicar os significados, as origens e causas da problemática ambiental, assim como as alternativas que são apresentadas, por diferentes atores sociais, para amenizar os seus efeitos.

Em muitas reflexões sobre a problemática ambiental, o núcleo dos argumentos gira em torno da ideia de que ela deve ser administrada tecnicamente. Uma das ideias centrais nesse tipo de reflexão é a de que as decisões importantes da sociedade devem ser tomadas por um corpo técnico qualificado.

Em perspectivas dessa natureza, frequentemente, aponta-se que os especialistas têm melhores condições para decidir sobre os processos que se destinam a amenizar os efeitos das diferentes problemáticas ambientais, sobretudo, devido aos seus conhecimentos técnicos específicos, que se pautam pela superioridade e neutralidade.

Concepções dessa natureza, segundo Auler e Delizoicov (2006), são aceitas, fomentadas ou elaboradas por determinados atores sociais interessados na disseminação de uma imagem de que a Ciência e a Tecnologia se pautam unicamente pelos conhecimentos sistematizados. Daí advém a ideia de que as decisões tomadas pelos seus legítimos representantes são orientadas pela isenção de valores e pela neutralidade política, econômica e religiosa. Além disso, como complemento a essa compreensão, os autores destacam a existência de proposições que possuem, como núcleo, a ideia de que "os problemas hoje existentes, e os que vierem a surgir, serão automaticamente resolvidos com o desenvolvimento cada vez maior da Ciência e Tecnologia (CT), estando a solução em mais e mais CT [...]" (AULER; DELIZOICOV, 2006, p. 343). Para esses autores, proposições dessa natureza secundarizam as relações sociais em que a Ciência e Tecnologia são concebidas e utilizadas.

Do mesmo modo, Moraes (2002), ao analisar as concepções dos cientistas sociais sobre a temática ambiental, destaca que uma parte desta é eminentemente tecnicista. Para o autor, concepções dessa natureza colocam em segundo plano a dimensão social da temática ambiental, ao diluírem as implicações políticas de seu manejo - como se as soluções técnicas não envolvessem decisões políticas, interesses, projetos, perspectivas conflitantes etc. O discurso pautado pelo tecnicismo objetiva autonomizar a Ciência em relação à sociedade que a gerou, pondo a técnica como algo acima dos conflitos e das disputas. A perspectiva tecnicista leva-nos a acreditar que a Ciência e a Tecnologia são as únicas alternativas viáveis para a superação da problemática ambiental.

Moraes (2002) também destaca outras concepções sobre a temática ambiental - o naturalismo e o romantismo. No naturalismo, a problemática ambiental também perde totalmente a sua dimensão social. Trata-se, pois, 
A temática ambiental e as diferentes compreensões ...

[...] daqueles discursos que vêem o homem apenas como fator de alteração do equilíbrio de um meio; daquelas análises que não falam de sociedade mas apenas da ação antrópica, uma variável a mais num conjunto de fatores basicamente naturais. A relação ser humano-natureza é concebida sem a mediação das relações sociais. (MORAES, 2002, p. 55)

Se no caso do naturalismo a dimensão política está ausente, no romantismo há uma excessiva politização das análises, na maioria das vezes com fundamentações frágeis ou inadequadas. Ainda segundo Moraes (2002, p. 54):

Temos muito uma espécie de bom senso bem intencionado, ingênuo, ao tomar a política como reino da pura vontade - como se a política não tivesse sua lógica e suas determinações. Exemplos desse tipo de manifestações românticas: preservacionismo radical - natureza colocada como um valor muito superior que o ser humano.

Carvalho (1989) aponta que outras concepções sobre a relação sociedade-natureza enfatizam a ideia de que a degradação ambiental é o preço a ser pago pelo progresso material da sociedade. Essa espécie de passividade diante da concepção de "desenvolvimento" carrega consigo algumas semelhanças com a concepção tradicional de progresso. É interessante destacar que Auler e Delizoicov (2006) indicam que a concepção tradicional de progresso traz consigo a ideia da defesa do determinismo tecnológico, ou seja, uma forma sutil de negar as potencialidades e a relevância da ação humana.

É também relevante destacar aquelas concepções mais críticas sobre a relação sociedade-natureza. A essência dessas concepções reside na ideia de que a origem ou causa da problemática ambiental está diretamente articulada à forma como pensamos e nos relacionamos com o mundo, ou seja, nas palavras de Borheim (1995), à forma como tornamos a natureza presente.

Para autores como Leff $(2002,2006)$, a partir do advento da modernidade, o homem, em sua ânsia de unificar, universalizar e homogeneizar o mundo, acabou consolidando o germe da heterogeneidade e da diversidade. Nesse processo, foi gerada uma ordem desigual, dispersa e contraditória, pois, se de um lado as várias ordens da racionalidade modernizadora - econômica, tecnológica, jurídica - se articularam para criar a ideia de globalização do mundo através do mercado, do outro lado, dão lugar a uma tendência que, buscando desprender-se da tradição e desencadear uma revolução permanente da novidade, leva à multiplicação das modas e do consumo.

Segundo Leff (2002), todas essas contradições nos remetem a uma crise de proporções ainda mal estimadas, ou seja, no momento em que nos imaginamos senhores e possuidores da natureza, fomos brindados com uma crise ambiental de consequências planetárias imprevisíveis. Nesse sentido, o autor aponta que a problemática ambiental surge nas últimas décadas do século XX como uma crise de civilização, uma crise que questiona a racionalidade econômica e tecnológica dominantes e, de forma mais ampla, o próprio conhecimento do mundo. 
Essas diferentes concepções sobre a relação sociedade-natureza influenciam a construção das diferentes proposições políticas formuladas pelos setores organizados da sociedade. Essas proposições revestem-se de grande significado para as nossas práticas sociais, e aqueles que assim entendem têm valorizado, enfaticamente, a incorporação da temática ambiental em espaços e processos educacionais formais ou não formais.

Considerando a diversidade e a importância das diferentes compreensões sobre a problemática ambiental, parece-nos significativo indagarmos: quais os possíveis reflexos e consequências dessas compreensões sobre as origens, causas e consequências da problemática ambiental para nossas práticas pedagógicas no Ensino Superior e no Ensino Básico?

Parece-nos claro que as críticas e as ideias propositivas construídas pelos ambientalistas e intelectuais dos diferentes ramos do conhecimento questionam as dimensões teóricas e metodológicas de nossas práticas educativas. Nesses termos, não podemos ficar indiferentes à problemática ambiental e às importantes indagações construídas por parte do movimento ambientalista, sob o risco de ficarmos indiferentes ao próprio processo da nossa história. Assim, ao considerarmos as sínteses inovadoras, as críticas aos padrões de organização social e as proposições de novos paradigmas promovidas por alguns setores mais críticos do movimento ambientalista, podemos postular diferentes implicações para nossas propostas de práticas de ensino, sobretudo, para aquelas que relacionam, de alguma forma, a temática ambiental ao ensino das Ciências Naturais.

É importante destacar que os questionamentos colocados por aqueles que se propõem a compreender a problemática ambiental revestem-se de grande significado para pensarmos nossas práticas de ensino de Ciências da Natureza e, de modo particular, de ensino de Física.

Contudo, em relação ao ensino de Física, há vários aspectos que parecem dificultar a realização de atividades de ensino que incorporem os questionamentos colocados pelos setores mais críticos do movimento ambientalista. Entre essas dificuldades, certamente, se destacam aquelas diretamente relacionadas com a possibilidade de abordagens mais complexas da relação ciência-tecnologia-sociedade-ambiente. Nesse sentido, ainda prevalece, em muitas práticas de ensino de Física, a concepção de um conhecimento científico factual e conceitual. Brito et al. (2008) e Silva (2007) indicam que esses aspectos relacionados com um ensino de Ciências mais tradicional são tão significativos que alguns professores não se identificam com a possibilidade de abordar outros aspectos da realidade em suas práticas de ensino.

No entanto, dada a complexificação das diferentes práticas sociais que conformam, hoje, padrões também complexos das diferentes dimensões da realidade, incluindo os processos de produção de conhecimento sobre a natureza, uma visão reducionista sobre o ensino das ciências naturais pode trazer consequências comprometedoras para a formação de cidadãos engajados e socialmente ativos.

Assim, partimos do pressuposto de que as concepções que os professores e futuros professores elaboram e constroem sobre esses diferentes processos de complexificação da realidade socioambiental são de grande relevância para suas tentativas de realizar abordagens mais complexas e realistas em suas atividades de ensino.

Tendo em conta que as concepções de futuros professores de Física sobre a temática ambiental podem vir a ser um grande obstáculo para a realização de atividades de ensino que envolvam aspectos dessa temática, e considerando as perspectivas propostas pelo movimento 
A temática ambiental e as diferentes compreensões ...

ambientalista e as diferentes possibilidades de inseri-las em nossas práticas de ensino de Físi$\mathrm{ca}$, delineamos um projeto de pesquisa com o seguinte objetivo mais geral: identificar as concepções de um grupo de futuros professores de Física relacionadas com a problemática ambiental, e analisar práticas pedagógicas que articulam atividades de ensino de Física com a temática ambiental por eles proposta.

Neste artigo, em particular, colocamo-nos frente aos seguintes questionamentos: qual a concepção de futuros professores de Física em relação aos aspectos da temática ambiental? Que propostas são elaboradas pelos futuros professores de Física que decidem abordar alguns aspectos da problemática ambiental em suas atividades de ensino? Que obstáculos se apresentam a esses futuros professores de Física em tentativas como essas?

\section{O contexto da pesquisa}

Este artigo é parte de uma pesquisa mais ampla que procurou analisar o significado de conhecimento e, especificamente, de conhecimento escolar, presente nas propostas e práticas de ensino dos estudantes de licenciatura em Física que consideram aspectos da temática ambiental a partir de temas controversos.

Outro aspecto relevante do contexto desta investigação é o fato de que, durante a sua realização, um dos autores era professor dos licenciandos de um curso de Física de uma universidade pública localizada no estado de São Paulo. Desse modo, a coleta de dados foi realizada durante um ano letivo, a partir da elaboração e execução de um projeto de intervenção em duas disciplinas obrigatórias para o curso de Licenciatura em Física - Prática de Ensino e Estágio Supervisionado de Física I e II.

É importante mencionar que a Prática de Ensino é o momento privilegiado para que o futuro professor aprofunde a sua compreensão da realidade do ensino e tenha um contato direto com a escola de Educação Básica e com a prática docente para a qual está se preparando. Essa disciplina também constitui um ponto de referência para a articulação dos conteúdos específicos com os conteúdos pedagógicos.

Além disso, salientamos que, durante as disciplinas Prática de Ensino e Estágio Supervisionado de Física I e II, incentivamos os futuros professores de Física a elaborarem propostas de ensino contextualizadas a partir de aspectos da temática ambiental. De modo especial, apresentamos e discutimos alguns caminhos para articular os conteúdos específicos da Ciência e da Tecnologia com importantes aspectos sociais e ambientais, sempre com base em uma perspectiva mais crítica do processo educativo.

Para elaborar e executar as propostas de ensino, os licenciandos foram divididos em grupos de até quatro componentes. Na Prática de Ensino I, foram formados seis grupos e, na Prática de Ensino II, oito grupos. Esses grupos foram formados pelos próprios estudantes, conforme suas afinidades. A partir de então, os estagiários elaboraram um minicurso, com quatro aulas de 50 minutos cada. Esses grupos tiveram total liberdade de escolha dos temas a serem trabalhados com alunos do Ensino Médio de uma escola pública. 


\section{Procedimentos metodológicos}

Com base nas características gerais da pesquisa qualitativa, a possibilidade de realizar uma intervenção planejada pareceu-nos a alternativa mais viável para o processo de coleta de dados. Conforme explicita André (1998), nesse tipo de investigação, o pesquisador realiza a coleta dos dados enquanto se desenvolvem as atividades de ensino e aprendizagem em sala de aula.

Na primeira etapa - o planejamento - elaboramos os objetivos da pesquisa e o plano de ensino para as disciplinas Prática de Ensino e Estágio Supervisionado de Física I e II. A partir desses planos, foi possível prever alguns eventos mais significativos em termos de coleta de dados para esta pesquisa. Foi também nessa etapa do trabalho que elaboramos atividades de ensino que, além de estarem sintonizadas com os objetivos pedagógicos do curso, deveriam contemplar a possibilidade de coleta de dados para a pesquisa.

Na segunda etapa - o monitoramento - realizamos a intervenção nas aulas de Prática de Ensino e Estágio Supervisionado de Física I e II. Monitoramos o processo de desenvolvimento das disciplinas e procedemos à coleta dos dados.

Neste trabalho, de modo especial, os dados apresentados foram obtidos através dos seguintes procedimentos: questionários abertos, análise das diferentes versões dos planos de ensino construídos pelos estagiários, entrevista semiestruturada e observação direta das aulas dos estagiários.

Os questionários abertos constituíram um registro em primeira mão para identificarmos algumas ideias dos futuros professores de Física em relação aos aspectos da problemática ambiental e à possibilidade de abordá-los em proposições educativas.

As entrevistas foram conduzidas a partir de determinados tópicos, ou, em outros termos, foram orientadas por questões mais gerais. Um desses tópicos solicitava, dos licenciandos, um posicionamento sobre a possibilidade de tratar aspectos da problemática ambiental em aulas de Física. Vale destacar que, ao todo, foram realizadas oito entrevistas, ou seja, uma com cada grupo de dois ou três estagiários, de acordo com o agrupamento que eles utilizaram para construir e efetivar as propostas de trabalho no estágio supervisionado. Essas entrevistas ocorreram no final da disciplina Prática de Ensino e Estágio Supervisionado de Física II, momento em que todos os grupos de estagiários já haviam ministrados seus minicursos.

Recolhemos todos os planos de ensino elaborados pelos estagiários. $\mathrm{Na}$ disciplina Prática de Ensino I, os licenciandos elaboraram uma versão do plano de ensino, ao passo que na Prática de Ensino II foram elaboradas três versões do plano.

A observação direta das aulas dos estagiários foi realizada com o auxílio de uma filmadora. Os dados foram posteriormente transcritos em computador por meio de um editor de texto.

Para analisar os dados obtidos, procuramos identificar evidências dos posicionamentos e das compreensões dos futuros professores em relação aos aspectos da problemática ambiental. De maneira especial, procuramos identificar os caminhos e os obstáculos que se apresentam aos estagiários que decidem tratar aspectos da problemática ambiental em suas propostas de ensino.

Em uma primeira fase do processo de análise de dados, realizamos a leitura dos documentos coletados na íntegra. Posteriormente, realizamos outras leituras com a finalidade 
A temática ambiental e as diferentes compreensões ...

de construir agrupamentos de análise, ou seja, uma operação de classificação daqueles elementos representativos das ocorrências regulares. Vale destacar que essa etapa da pesquisa consiste em descobrir os núcleos de sentido que compõem a comunicação e que podem apontar para significados que estão sendo construídos pelos futuros professores sobre processos relacionados com o tema desta investigação. Nessa etapa elaboramos fichas de leitura, que foram identificadas com a data e o título da atividade de coleta de dados desenvolvida. Registramos, nessas fichas, passagens ou excertos que ofereciam elementos para identificarmos as concepções dos licenciandos em relação à temática ambiental. Ressaltamos que os excertos foram associados a nomes fictícios e, dessa forma, preservamos a identidade dos licenciandos participantes da presente investigação. Posteriormente, esses excertos foram utilizados em quadros para exemplificar o núcleo de sentido presente em determinados agrupamentos.

\section{A concepção dos futuros professores de Física em relação à temática ambiental}

Durante a intervenção que realizamos nas disciplinas Prática de Ensino e Estágio Supervisionado de Física I e II, procuramos, primeiramente, obter dados que nos indicassem a concepção dos futuros professores em relação aos aspectos da temática ambiental.

Em uma das primeiras atividades realizadas na disciplina Prática de Ensino I, solicitamos, aos estagiários, que respondessem a um questionário. Esse questionário era composto por apenas uma pergunta, que solicitava, dos futuros professores, a enumeração dos principais problemas existentes na sociedade atual. A pergunta estava assim formulada: "Quais são, na sua opinião, os problemas mais graves que existem na sociedade atual?".

A questão proposta aos futuros professores procurava, dessa forma, indícios sobre possíveis associações estabelecidas por eles entre os problemas compreendidos como os mais graves para a sociedade e aqueles relacionados com problemas ambientais.

Dos 18 estudantes que frequentavam as aulas de Prática de Ensino e Estágio Supervisionado de Física I (16 homens e duas mulheres), 13 estavam presentes nesse encontro e responderam ao questionário. A partir da leitura e análise das respostas dos estagiários, percebemos que apenas um deles aponta, explicitamente, os impactos ambientais como um dos principais problemas da sociedade. Vale citar que esse estagiário faz duas menções aos aspectos da problemática ambiental numa lista que contém 18 itens. Destacamos, assim, a sua resposta:

Exclusão social; desemprego; violência; pobreza; fome; desrespeito pelo meio ambiente; poluição; falta de educação (instrução e conbecimento); falta de solidariedade e fraternidade; orgulho e egoismo; êxodo rural; sem-terra e sem-habitação; modelo econômico baseado no mercado financeiro; falta de amparo à velhice; o sistema de saúde. (Emílio)

Em outra atividade escrita realizada na disciplina Prática de Ensino e Estágio Supervisionado de Física I, solicitamos, aos alunos, que dessem a sua opinião quanto à importância dos problemas ambientais. A questão foi assim apresentada aos sujeitos da pesquisa: "Você acha que os problemas ambientais são importantes? Explique". 
Silva, L. F.; Carvalho, L. M.

Ao contrário das questões anteriores, essa explicita claramente a existência de problemas ambientais e solicita, aos licenciandos, um posicionamento diante deles.

Dos 18 alunos que frequentavam o curso, 10 estavam presentes e responderam ao questionário. A partir da sistematização e análise das respostas, pudemos agrupar as explicações apresentadas pelos estagiários em diferentes grupos, considerando alguns núcleos nas justificavas por eles apresentadas (Quadro 1).

Quadro 1. Justificativas apresentadas pelos alunos do curso de Licenciatura em Física de uma universidade pública, matriculados na disciplina Prática de Ensino I, em relação à importância atribuída aos problemas ambientais.

\begin{tabular}{|l|c|l|}
\hline \multicolumn{1}{|c|}{ Justificativas } & $\begin{array}{l}\text { Número de } \\
\text { indicações }\end{array}$ & \multicolumn{1}{|c|}{ Exemplo } \\
\hline $\begin{array}{l}\text { A relação direta com a vida } \\
\text { (com a experiência) aponta a } \\
\text { importância desse problema }\end{array}$ & 5 & $\begin{array}{l}\text { Sim. Os problemas ambientais estão ligados diretamente em } \\
\text { nossas vidas e, portanto, acaba sendo repetitivo dizer que } \\
\text { são importantes [sic]. (Carolina) }\end{array}$ \\
\hline $\begin{array}{l}\text { Há uma relação entre os } \\
\text { problemas ambientais e } \\
\text { outros problemas }\end{array}$ & 4 & $\begin{array}{l}\text { Problemas ambientais tais como a poluição do ar têm } \\
\text { afetado, e muito, a vida das pessoas, principalmente das } \\
\text { que vivem nas grandes metrópoles, causando problemas } \\
\text { nos sistemas respiratórios, alergias, ardência nos olhos } \\
\text { dentre outros problemas [sic]. (Beatriz) }\end{array}$ \\
\hline $\begin{array}{l}\text { Relação entre atitudes mais } \\
\text { imediatas da população e } \\
\text { efeitos percebidos na fauna e } \\
\text { flora }\end{array}$ & 1 & $\begin{array}{l}\text { Os lixos que são jogados nos rios (lixos caseiros e } \\
\text { industriais) têm causado a poluição dos nossos rios e } \\
\text { consequentemente a matança das nossas faunas e floras } \\
\text { marinhas [sic]. (Beatriz) }\end{array}$ \\
\hline $\begin{array}{l}\text { Manutenção da vida no } \\
\text { planeta }\end{array}$ & 1 & $\begin{array}{l}\text { Quando alteramos algo no ambiente, a curto ou longo prazo, } \\
\text { estaremos mudando algo em nós mesmos [sic].Mudanças } \\
\text { drásticas no ambiente (como a destruição da camada de } \\
\text { ozônio, por exemplo) não deslocar[ão] a [T]erra de sua } \\
\text { órbita, mas com certeza tornar[ão] o planeta um lugar } \\
\text { inabitável para a maioria dos seres vivos". (Glauco) }\end{array}$ \\
\hline
\end{tabular}

Fonte: Silva (2007).

Observamos que as justificativas que têm como núcleo de seus argumentos a relação direta entre "problemas ambientais" e a vida, são as mais frequentes entre os estagiários. As justificativas incluídas nesse grupo fazem referência às experiências vivenciadas pelos estagiários.

Os dados coletados por meio desse questionário ainda nos indicaram que alguns estagiários fizeram uma tentativa de apontar possíveis caminhos para diminuir ou, em alguns casos, reverter o processo de degradação ambiental. Seis futuros professores de Física citam algumas possibilidades de reversão do quadro de degradações ambientais. Entre esses, quatro explicitam a contribuição da prática educativa a esse processo. Exemplo:

Os problemas ambientais são de grande importância para a sociedade... Um modo mais rápido de atingir os habitantes de nosso planeta no futuro para que tenham consciência dos problemas ambientais é o de acrescentar uma disciplina ou tópicos em diversas disciplinas sobre o tema. Um bom tópico que um professor de Física 
A temática ambiental e as diferentes compreensões ...

poderia tratar na sua aula de termodinâmica seria como o planeta está esquentando [sic]. Já um professor de química trataria como ocorrem as reações para a formação de buraco na camada de ozônio [sic]. Existem tantos outros temas que poderiam ser colocados nessa discussão. Com isso, desde cedo, as pessoas se tornariam mais críticas e participativas para ofim dos problemas ambientais [sic]. (Henrique)

Nesse argumento, o estagiário propõe que os professores de Ciências Naturais passem a tratar aspectos da temática ambiental com a finalidade de oferecer ferramentas técnicas e conceituais para que as pessoas entendam a problemática ambiental e se posicionem diante da mesma.

Destacamos, também, que seis futuros professores de Física, entre os 10 que responderam ao questionário que solicitava um posicionamento sobre a importância atribuída aos problemas ambientais, apontaram possíveis razões para a existência desses problemas. No Quadro 2, sumariamos as principais compreensões dos futuros professores sobre as causas da existência dos problemas ambientais.

Três estagiários atribuem, às aplicações da Ciência e da Tecnologia, as causas para os problemas ambientais. Essa visão que coloca a Ciência e a Tecnologia como os únicos responsáveis pelos problemas ambientais pode ser comparada, conforme identificamos no trabalho de Auler e Delizoicov (2006), a uma espécie de determinismo tecnológico, ou seja, ignoram-se as relações sociais em que a Ciência e a Tecnologia são produzidas e utilizadas.

Já no grupo de respostas que denominamos modelos de produção social, reunimos os argumentos que indicam serem os meios de produção social os principais responsáveis pela degradação ambiental. Essa visão sobre a problemática ambiental também não apresenta articulações entre as diferentes dimensões da realidade. Há, mesmo, uma simplificação das prováveis causas da problemática ambiental ao serem tomados os modelos de produção social desvinculados de outras dimensões da realidade.

De maneira geral, as visões sobre a problemática ambiental que os licenciandos em Física apresentam nesses questionários são pouco articuladas com outros aspectos da realidade. Os dados indicam que eles não vinculam espontaneamente, nem de modo mais complexo, as causas dos problemas ambientais com diferentes dimensões da realidade, tais como a do conhecimento, da prática política e da prática valorativa, ou, ainda, com aspectos do enfoque Ciência, Tecnologia, Sociedade e Ambiente (CTSA). Observamos que há, de maneira geral, uma tendência a compartimentalizar as causas da degradação ambiental. Além disso, a maioria deles utiliza argumentos mais descritivos e, raramente, questiona a maneira como construímos nossa relação com a natureza ou como estamos organizados socialmente.

Tendo em conta esse contexto, procuramos analisar as propostas elaboradas pelos licenciandos que tentaram articular alguns aspectos da temática ambiental com o ensino de Física. 
Silva, L. F.; Carvalho, L. M.

Quadro 2. Causas dos problemas ambientais atribuídas pelos alunos do curso de Licenciatura em Física, de uma universidade pública, matriculados na disciplina Prática de Ensino I.

\begin{tabular}{|l|c|l|}
\hline $\begin{array}{c}\text { Causas dos problemas } \\
\text { ambientais }\end{array}$ & $\begin{array}{l}\text { Número de } \\
\text { indicações }\end{array}$ & \multicolumn{1}{|c|}{ Exemplo } \\
\hline Científico-tecnológico & 3 & $\begin{array}{l}\text { A evolução da ciência, da tecnologia (levando em conta a mais } \\
\text { rústica delas também) proporciona muitos avanços e muitas } \\
\text { novidades a serem pesquisadas, mas também teve como preço (e } \\
\text { alto) a poluição do nosso meio ambiente. (Douglas) }\end{array}$ \\
\hline $\begin{array}{l}\text { Modelos de produção } \\
\text { social }\end{array}$ & 2 & $\begin{array}{l}\text { É possível mostrar a influência e os impactos ambientais causados } \\
\text { pela ação inconsequente do homem. Mostrar o desmatamento, a } \\
\text { degradação de energia e fontes minerais devido à ganância de } \\
\text { desenvolvimento, tanto material como econômico, do homem [sic]. } \\
\text { (Alberto) }\end{array}$ \\
\hline $\begin{array}{l}\text { Manejo inadequado de } \\
\text { resíduos }\end{array}$ & 1 & $\begin{array}{l}\text { Os lixos que são jogados nos rios (lixos caseiros e industriais) têm } \\
\text { causado a poluição dos nossos rios e consequentemente a } \\
\text { matança das nossas faunas e floras marinhas [sic]. (Beatriz) }\end{array}$ \\
\hline
\end{tabular}

Fonte: Silva (2007).

Compreensões dos futuros professores de Física sobre a temática ambiental e suas iniciativas em elaborar proposições educativas relacionadas ao tema

Entre as atividades que os estagiários realizaram nas disciplinas Prática de Ensino e Estágio Supervisionado I e II, destacamos as suas propostas ou planos de ensino. Procuramos analisar as propostas de ensino planejadas por aqueles futuros professores de Física que se propuseram a tratar aspectos da temática ambiental. Buscamos, também, compreender quais fatores facilitam ou dificultam o trabalho educativo dos estagiários em relação a essa temática.

$\mathrm{Na}$ disciplina Prática de Ensino e Estágio Supervisionado de Física I, nenhum dos futuros professores de Física planejou atividades de ensino que abordassem aspectos da temática ambiental. Eles apresentaram certa dificuldade, alguns, até mesmo, uma resistência em tratar outros aspectos da realidade em seus planos de ensino.

No entanto, na disciplina Prática de Ensino e Estágio Supervisionado de Física II, cinco grupos de estagiários de um total de oito apontam possibilidades de tratar alguns aspectos da temática ambiental.

A partir da leitura das diferentes versões dos planos de ensino dos estagiários, identificamos que, de modo geral, no item "objetivos" da proposta, é que mais frequentemente surgem as indicações sobre aspectos da temática ambiental. Aliás, essa foi a opção unânime entre aqueles que destacam aspectos da problemática ambiental em suas propostas de ensino.

Embora os estudantes de Licenciatura em Física que participaram desta pesquisa tenham indicado, nos objetivos de seus planos de ensino, a intenção de explorar, nos cursos que estavam sendo planejados aspectos da problemática ambiental, notamos que, na maioria das vezes, essa indicação não é acompanhada pela descrição dos conteúdos específicos a serem abordados e/ou dos procedimentos a serem adotados em sala de aula. Essa situação é um indicativo de certa dificuldade dos estagiários em traduzir esses objetivos em outros itens de suas propostas de ensino. Nesse caso, a apresentação dos aspectos relacionados com a 
A temática ambiental e as diferentes compreensões ...

problemática ambiental no item "objetivos" representa para eles, ao menos nesse momento, uma carta geral de intenções e/ou uma primeira tentativa de aproximação com essa temática.

As informações obtidas com as três versões dos planos de ensino dos estagiários ainda nos permitiram identificar quais os conteúdos de Física que favoreciam, segundo a ótica dos futuros professores, trabalhos educativos com aspectos da temática ambiental. O Quadro 3 sumaria as indicações dos futuros professores de Física.

Quadro 3. Conteúdos de Física que, segundo os diferentes grupos de trabalho dos alunos do curso de Licenciatura em Física de uma universidade pública, matriculados na disciplina Prática de Ensino II, favorecem a abordagem de aspectos da temática ambiental.

\begin{tabular}{|l|l|}
\hline Grupo & \multicolumn{1}{|c|}{ Temas propostos } \\
\hline Grupo 1 & Termodinâmica \\
\hline Grupo 2 & Cinemática \\
\hline Grupo 3 & Energia mecânica e elétrica \\
\hline Grupo 4 & Ondulatória e ondas eletromagnéticas \\
\hline Grupo 5 & Ondas eletromagnéticas e decaimento radioativo \\
\hline
\end{tabular}

Fonte: Silva (2007).

Os dados coletados por meio da transcrição das aulas dos estagiários possibilitaramnos identificar os caminhos escolhidos pelos futuros professores para a inserção da temática ambiental em suas atividades de ensino de Física. De modo geral, os aspectos da temática ambiental eram utilizados para exemplificar/ilustrar um determinado conceito físico. Percebese que a perspectiva de exemplificar/ilustrar a aplicação dos conteúdos específicos a partir de aspectos da temática ambiental constituiu-se, para os licenciandos, em uma primeira tentativa de, ao menos, tratar alguns desses aspectos em suas atividades de ensino.

Com a finalidade de entender o processo que levou os estagiários a abordarem aspectos da temática ambiental em seus planos, destacamos algumas atividades nas quais essa questão pôde ser analisada. Em uma delas, os futuros professores deveriam analisar a primeira versão do plano de ensino entregue na disciplina Prática de Ensino II. Os estagiários foram convidados a realizar um exercício que lhes solicitava uma análise crítica de seus próprios planos de ensino a partir de um roteiro de trabalho contendo quatro questões. A partir desse roteiro, os futuros professores identificaram se, em seus planos de ensino, haviam considerado as principais tendências curriculares para a área de ensino de Física e, também, outras dimensões da realidade, tais como as relacionadas com a temática ambiental.

Nesse momento, destacamos a resposta de Carolina, estagiária que participou de um grupo que fez a tentativa de levar, para seus planos, alguns aspectos da temática ambiental. Para ela, o tratamento de aspectos dessa temática em aulas de Física é mais afeito a um trabalho interdisciplinar envolvendo, sobretudo, as áreas disciplinares de Biologia e Geografia.

Além disso, existe um aspecto que pode ser trabalbado de modo interdisciplinar com a biologia, que é o aspecto ambiental, por sinal, muito discutido atualmente. Este aspecto também será tratado em nosso trabalho e com grande ênfase. Também 
Silva, L. F.; Carvalho, L. M.

considero que nosso plano de aula está "seguindo" as tendências recentes, pois trabalharemos um pouco de história e de como tudo começou e por que usamos mais bidroelétricas, entrando um pouco na área de geografia e também um pouco em política, afinal, por que temos que ter usinas termoelétricas e nucleares em nosso país se podemos contar com solares e eólicas. Portanto, acredito que estamos considerando, sim, as recentes tendências para o ensino de Física. (Carolina)

Avaliamos que muitos licenciandos em Física não consideram que a abordagem de aspectos da temática ambiental possa se configurar como conteúdo de sua disciplina. De fato, é isso o que ocorre quando eles sugerem um trabalho interdisciplinar para tratar aspectos da temática ambiental em suas atividades de ensino. Como mostraremos na sequência, vários estagiários sequer consideram que a contextualização dos conteúdos específicos de Física, a partir da temática ambiental, deva ser trabalhada na escola por professores de Física. Para a maioria deles, esses aspectos devem ser tratados, exclusivamente, por professores de outras especialidades, tais como Biologia e Geografia.

O estagiário Douglas relata, em depoimento coletado em entrevista, que os aspectos da temática ambiental não estão inseridos no campo teórico dos físicos. Nesse sentido, o licenciando indica que o trabalho educativo voltado para a discussão dos aspectos da temática ambiental estaria mais direcionado aos profissionais de outras áreas do conhecimento, como, por exemplo, biólogos e geógrafos: "Talvez se a gente imaginasse que isto tivesse mais a ver com ecologia, on seria uma aula de geografia, on de biologia [sic]."

Novamente, notamos que, para vários estagiários, a temática ambiental apresenta termos, conceitos, abordagens e caminhos metodológicos diferentes daqueles aprendidos e intensivamente trabalhados no curso de Licenciatura em Física. O trabalho educativo com aspectos dessa temática coloca os licenciandos diante de uma novidade surpreendente, põe em xeque as suas convicções disciplinares e traz à tona conhecimentos que eles antes relegavam a um segundo plano.

Em outro depoimento coletado em entrevista realizada no final da disciplina de Prática de Ensino II, Carolina argumenta que tem dificuldade em associar a discussão que envolve aspectos da temática ambiental com a Física.

Professor: Você encontrou alguma dificuldade em compreender a discussão que estava relacionada aos impactos ambientais?

Carolina: Não, isso não. O que eu tenho dificuldade é ver esta discussão relacionada com a Física.

Professor: Continue... a dificuldade era relacionar estes aspectos com a Física? Carolina: Então, se en fosse preparar uma aula... Bom, en não sei como faria agora, entende? Soziinha, ou seja, lá fora [em uma atividade profissional], eu não iria conseguir fazer essa contextualização.

Em outro momento ela ressalta o seguinte:

Carolina: Eu tenho a impressão de que não estou ensinando a Física. Não sei se foi pelo jeito que en aprendi, talvez a Física tenha ficado aqui [no curso de Física da universidade]!

Carlos: A Física do jeito que você aprendeu! 
A temática ambiental e as diferentes compreensões ...

Carolina: Mas para mim ficou tão marcado isso... que é difícil. Assim, parece que eu não vou conseguir dar conta dos conteúdos na escola. São 3 anos de Física (no ensino médio) e, se en fizer essa contextualização...

Professor: Você não dará conta do conteúdo programado?

Carolina: Sabe qual é o problema? Acho que por ter dado aula no cursinho eu fiquei viciada em terminar o conteúdo. Para mim isso é importante.

Para Carolina, é difícil abordar aspectos da temática ambiental em aulas de Física, tendo em conta a grande quantidade de conceitos a serem trabalhados no Ensino Médio. Destacamos que relatos desta natureza também indicam que os futuros professores de Física não entendem o tratamento dessa temática como parte do trabalho de um professor de Física.

Os argumentos que alguns licenciados apresentam com relação às dificuldades em tratar aspectos da temática ambiental em suas propostas e atividades de ensino também podem estar relacionados com o fato de que, durante seus processos formativos na Educação Básica e Superior, foram poucas as oportunidades que tiveram de vivenciar processos dessa natureza. No curso de Física desses licenciandos, por exemplo, não havia, até aquele momento, um direcionamento para que as disciplinas relacionassem aspectos da temática ambiental e o ensino de Física e/ou a Física. A discussão dessas possíveis articulações estava dependente das iniciativas de cada professor do curso, como, por exemplo, as realizadas nas disciplinas de Prática de Ensino e Estágio Supervisionado de Física I e II.

Nesse ponto, devemos insistir na ideia de que os cursos de formação inicial deveriam possibilitar que seus alunos vivenciassem processos educativos que articulassem os conteúdos específicos em contextos que relacionam, entre outros aspectos, a Ciência, a Tecnologia, a Sociedade e o Ambiente. Ressaltamos, entretanto, que esse processo de contextualização deve ser realizado a partir do reconhecimento das diferenças disciplinares, das singularidades, dos pontos de complementaridade e das limitações de cada campo específico de conhecimento.

\section{Considerações finais}

As concepções que os futuros professores de Física possuem sobre a temática ambiental podem tornar-se obstáculos para a incorporação desses aspectos em suas propostas de ensino.

Conforme já salientamos em nosso trabalho, não há, por parte dos futuros professores de Física, um entendimento mais amplo do significado da temática ambiental e suas consequências diretas e indiretas para nossas concepções de ensino e de práticas culturais e pedagógicas. Além disso, do ponto de vista da articulação entre a temática ambiental e o processo educativo, destacamos que a problemática ambiental é vista, pelos licenciandos em Física, como um tema voltado exclusivamente aos especialistas de algumas áreas específicas do conhecimento, como, por exemplo, a Biologia. Os estagiários reconhecem que os profissionais dessa área do conhecimento são as autoridades técnicas que devem tratar assuntos dessa natureza. Uma analogia cabível, nesse caso, poderia ser um biólogo dizendo que cabe, única e exclusivamente, aos físicos opinarem sobre a viabilidade da construção de usinas nucleares.

Porém, o ambiente não é apenas físico, químico ou biológico, do mesmo modo que não é apenas social, histórico e econômico; a temática ambiental envolve o diálogo entre os 
Silva, L. F.; Carvalho, L. M.

saberes sistematizados e entre estes e os conhecimentos populares ou do senso comum. Nessa perspectiva, o ambiente é um campo de problematização do conhecimento.

Percebemos, ao longo da investigação, que a temática ambiental exige, dos futuros professores de Física, mais que um contexto de aplicação das teorias físicas: ela traz à tona as incertezas e as complexidades inerentes a toda e qualquer atividade humana. As reflexões e os questionamentos formulados por aqueles que se propõem a pensar a problemática ambiental trazem à tona uma série de aspectos que estavam relegados ao esquecimento histórico.

É evidente que os estagiários encontram muitos obstáculos para trabalharem aspectos da temática ambiental; e um desses está diretamente relacionado com uma formação que privilegiou - ao longo do processo vivenciado na Escola Básica e no Ensino Superior - trabalhos educativos mais direcionados para o produto final da atividade científica.

Aliás, a tendência em apresentar o conhecimento científico livre de seu contexto e de suas controvérsias parece ser uma situação frequente em muitos cursos de formação inicial de professores de Física. Em determinadas situações vividas nas disciplinas Prática de Ensino e Estágio Supervisionado de Física I e II, alguns estagiários revelam que passam por um processo formativo, desde a escola básica até a superior, amplamente direcionado e baseado em aspectos conceituais das Ciências Naturais. Essas experiências de formação dificultam o planejamento e a execução de trabalhos educativos com outros aspectos da realidade. Nesse sentido, parece-nos evidente que atividades pedagógicas mais direcionadas para o produto final da atividade científica abstraem, do conhecimento científico, todo o seu caráter de processo e tornam-no asséptico, ou seja, livre das controvérsias que seus resultados apresentam. É também importante destacar que uma formação dessa natureza acaba consolidando, no futuro professor, uma determinada concepção sobre ensino de Física que, muitas vezes, se apresenta como obstáculo para perspectivas que apontam para a necessidade do diálogo de saberes. 
A temática ambiental e as diferentes compreensões ...

\section{Referências}

ANDRÉ, M. E. D. A. Desafios da pesquisa sobre a prática pedagógica. In: ENCONTRO NACIONAL DE DIDÁTICA E PRÁTICA DE ENSINO, 5., 1998, Lindóia. Anais... Lindóia: 1998. 1 CD-ROM.

AULER, D.; DELIZOICOV, D. Ciência-tecnologia-sociedade: relações estabelecidas por professores de ciências. Revista Electrónica de Enseñanza de las Ciencias, v. 5, n. 2, p. 337-355, 2006. Disponível em: < http://www.saum.uvigo.es/reec/volumenes/volumen5/ ART8_Vol5_N2.pdf>. Acesso em: 20 mar. 2007.

BORNHEIM, G. Filosofia e política ecológica. Revista Filosófica Brasileira, Rio de Janeiro, v. 1, n. 2, p. 16-24, 1995.

BRITO, L. D.; SOUZA, M. L.; FREITAS, D. Formação inicial de professores de ciências e biologia: a visão da natureza do conhecimento científico e a relação CTSA. Interacções, Santarém, v. 4, n. 9, p. 129-148, 2008. Disponível em: <http://nonio.eses.pt/interaccoes/ artigos/I7.pdf>. Acesso em: 15 dez. 2008.

CARVALHO, L. M. Temática ambiental e a escola de primeiro grau. 1989. 286 f. Tese (Doutorado em Educação) - Faculdade de Educação, Universidade de São Paulo, São Paulo, 1989.

LEFF, H. Epistemologia ambiental. São Paulo: Cortez, 2002.

Aventuras de la epistemología ambiental: de la articulación de ciencias al diálogo de saberes. México: Siglo XXI, 2006.

MORAES, A. C. R. Meio ambiente e ciências humanas. São Paulo: Hucitec, 2002.

SILVA, L.F. A temática ambiental, o processo educativo e os temas controversos: implicações teóricas e práticas para o ensino de física. 2007. 211 f. Tese (Doutorado em Educação) - Faculdade de Ciências e Letras, Universidade Estadual Paulista, Araraquara, 2007. 